\title{
Amy1, the $\alpha$-Amylase Gene of Aspergillus flavus: Involvement in Aflatoxin Biosynthesis in Maize Kernels
}

\author{
A. M. Fakhoury and C. P. Woloshuk
}

Department of Botany and Plant Pathology, Purdue University, West Lafayette, IN 47907.

Accepted for publication 24 June 1999.

\begin{abstract}
Fakhoury, A. M., and Woloshuk, C. P. 1999. Amyl, the $\alpha$-amylase gene of Aspergillus flavus: Involvement in aflatoxin biosynthesis in maize kernels. Phytopathology 89:908-914.

Aspergillus flavus is the causal agent of an ear and kernel rot in maize. In this study, we characterized an $\alpha$-amylase-deficient mutant and assessed its ability to infect and produce aflatoxin in wounded maize kernels. The $\alpha$-amylase gene Amyl was isolated from A. flavus, and its DNA sequence was determined to be nearly identical to Amy 3 of A. oryzae. When Amyl was disrupted in an aflatoxigenic strain of $A$. flavus, the mutant failed to produce extracellular $\alpha$-amylase and grew $45 \%$ the rate of the wild-type strain on starch medium. The mutant produced aflatoxin in medium con-

taining glucose but not in a medium containing starch. The $\alpha$-amylasedeficient mutant produced aflatoxin in maize kernels with wounded embryos and occasionally produced aflatoxin only in embryos of kernels with wounded endosperm. The mutant strain failed to produce aflatoxin when inoculated onto degermed kernels. In contrast, the wild-type strain produced aflatoxin in both the endosperm and embryo. These results suggest that $\alpha$-amylase facilitates aflatoxin production and growth of $A$. flavus from a wound in the endosperm to the embryo. A 14-kDa trypsin inhibitor associated with resistance to A. flavus and aflatoxin in maize also inhibited the $\alpha$-amylase from A. flavus, indicating that it is a bifunctional inhibitor. The inhibitor may have a role in resistance, limiting the growth of the fungus in the endosperm tissue by inhibiting the degradation of starch.
\end{abstract}

Aspergillus flavus causes an ear and kernel rot in maize. The disease is most severe when drought and high temperatures stress the host. Insect damage is also believed to increase disease incidence and severity. A. flavus produces aflatoxins, structurally related secondary metabolites that are products of the polyketide pathway. The fungus also produces aflatoxins in other seed crops such as peanuts, cottonseed, and tree nuts. The chemical nature of aflatoxin B1, a potent toxin and carcinogen, and its biosynthesis have been studied extensively. The mutagenicity of aflatoxin B1 to animals and humans is believed to involve oxidative activation by a cytochrome P450, in the liver and the kidney. An epoxide is created at the 8,9 position that reacts with the N7-guanine residues of DNA, causing mutations in the tumor repressor gene p53 (20).

Aflatoxin production is greatly affected by the type and quantity of carbon, nitrogen, and trace metals (18). In culture, the fungus produces greater levels of aflatoxin on simple sugars such as glucose, sucrose, and maltose than on more complex carbon sources such as starch and peptone (6). Although the metabolic basis for this phenomenon is not known, available evidence suggests that glycolysis has an important role in aflatoxin biosynthesis and that fermentable sugars are optimal carbon sources for aflatoxin production $(1,2)$. Maize genotypes with sugary kernels support more fungal growth and higher aflatoxin production than do genotypes with starchy kernels (25). Lipids in seeds can enhance the growth of $A$. flavus, but the stimulation of aflatoxin by seed lipids correlates with the potential for lipoperoxide formation $(7,12,14,22)$. Lipoperoxides are produced in many host-pathogen interactions by the oxidation of unsaturated lipids. Seeds with higher levels of polyunsaturated lipids have a higher potential for lipoperoxidation than do seeds with monounsaturated lipids. In support of this hy-

Corresponding author: C. P. Woloshuk

E-mail address: woloshuk@btny.purdue.edu

Publication no. P-1999-0819-03R

(C) 1999 The American Phytopathological Society pothesis, Fabbri et al. (12) showed that the addition of free radical generators to culture medium resulted in increased aflatoxin production by $A$. flavus, suggesting that aflatoxin protects the fungus against the free radicals associated with lipoperoxides. The nitrogen source can also influence the aflatoxin level produced in culture by A. flavus (18). Complex organic nitrogen sources such as peptone, yeast extract, and casamino acids result in higher aflatoxin production. Proline and asparagine are also stimulatory. In contrast, high nitrate concentrations suppress aflatoxin production. Finally, trace elements are essential for the growth of A. flavus and for aflatoxin production. When $A$. flavus is grown in zinc-deficient medium, aflatoxin production is low, but the presence of manganese in the medium inhibits aflatoxin production (18). Failla et al. (13) showed a positive correlation between aflatoxin production and the zinc content in maize kernels, but they found no correlation between manganese content and aflatoxin production.

Our previous research has attempted to identify host factors that are involved in susceptibility to A. flavus and aflatoxin production (15). With a GUS-reporter assay, we detected an aflatoxin-inducing activity in kernel extracts colonized by A. flavus (15). The inducing activity was determined to be glucose, maltose, and maltotriose. Evidence of $\alpha$-amylase ( $\alpha$-1,4-glucanhydrolase, EC 3.2.1.1) present in the kernel extracts suggested that these sugars were produced by the action of $\alpha$-amylase from A. flavus on kernel starch. To investigate the importance of $\alpha$-amylase in aflatoxin production, the $\alpha$-amylase gene was disrupted in an aflatoxigenic strain of $A$. flavus by gene disruption. In this study, we characterized an $\alpha$-amylasedeficient mutant and assessed its ability to infect and produce aflatoxin in wounded maize kernels.

\section{MATERIALS AND METHODS}

Fungal strains and growth media. Strain 118 (tan, $\arg 2$ ) of $A$. flavus was obtained from the collection of K. E. Papa, which is deposited at the U.S. Department of Agriculture Northern Regional Research Center in Peoria, IL. Strain 86-10D (whi, pyr, arg7) was obtained from G. A. Payne (North Carolina State University, Ra- 
leigh) who mutated strain 86 (whi, arg7) from the collection of K. E. Papa. Strains 86 and 118 are two aflatoxin-producing auxotrophs obtained by K. E. Papa from the mutagenesis of strain PC7. Fungal cultures were maintained on potato dextrose agar (PDA) medium amended with $10 \mathrm{mM}$ uracil when needed. Cultures were incubated at $37^{\circ} \mathrm{C}$.

DNA analysis. Plasmid DNA was isolated following the protocols described by Maniatis et al. (19). Transformation into Escherichia coli strain XL1-Blue (Stratagene Inc., La Jolla, CA) was by electroporation with a Gene Pulser II (Bio-Rad Laboratories, Hercules, CA). Fungal genomic DNA isolation and Southern hybridization analysis were performed as previously described (28). Sequencing was performed on both DNA strands by the DNA Sequencing Facilities at Iowa State University (Ames). DNA sequences were analyzed with the MacDNAsis program (Hitachi Software, San Bruno, CA). Database searches were done via Blast (National Center for Biotechnology Information, Bethesda, MD). The sequence of Amyl has been submitted to GenBank and given the number AF139925.

Amy1 disruption. A DNA fragment containing 1.2 kilobases (kb) of the $\alpha$-amylase gene Amyl from A. flavus was amplified by polymerase chain reaction (PCR). Protocols for PCR were as described by Egel et al. (11) with primers P1 (5'-ggatcgatttgcaaggacgg$\left.3^{\prime}\right)$ and P2 (5'-tagaggtcgtccatgctgcc-3'). The amplified DNA fragment was radio-labeled with the Prime It II random primer kit (Stratagene Inc.) and was used to probe an A. flavus genomic library (29). One clone containing Amyl was identified. Subsequently, a 2-kb Pst I-XbaI fragment of Amyl was cloned into pBluescript (Stratagene Inc.). A gene-disruption vector, WE55-13 (Fig. 1), was constructed by inserting the Pyr4 gene from Neurospora crassa into the SmaI site of the Amyl fragment. Following the technique described by Woloshuk et al. (30), protoplasts of A. flavus strain 86$10 \mathrm{D}$ were transformed with the disruption vector that was linearized with PstI. Transformants were selected by their ability to grow on media lacking uracil. $\alpha$-Amylase-deficient mutants were identified by PCR with primers P1 and P5 (5'-gaagcgcctcagggcgacgg- $\left.3^{\prime}\right)$. Other PCR primers used to characterize the insertion of WE-5513 were P3 (5'-ttgggcgtggcatcatcac- $\left.3^{\prime}\right)$ and P4 (5'-gaatgggcttcacagccatc- $\left.3^{\prime}\right)$.

Aflatoxin induction. Induction of aflatoxin production was determined by a replacement medium assay described by Flaherty et al. (15). Microtiter plates (24 wells) containing $1 \mathrm{ml}$ of peptone mineral salts (PMS) medium $(1,2)$ were inoculated with $A$. flavus conidia $\left(5 \times 10^{6}\right)$. The microtiter plates were incubated at $28^{\circ} \mathrm{C}$ for 2 days. The medium was then removed and replaced with starch $(2 \%)$, glucose $(2 \%)$, or PMS. The plates were incubated for 2 days at room temperature, at which time the mycelium and the liquid medium were collected together and mixed with acetone $(0.4 \mathrm{ml})$. After incubating overnight, the aflatoxin was extracted and partitioned into chloroform.

Aflatoxin analysis. Extracts from kernels, culture media filtrates, and mycelia were spotted on thin-layer chromatography (TLC) plates (K5 silica gel; Whatman, Clifton, $\mathrm{NJ}$ ), and the plates were developed in ether/methanol/water (96:3:1). Aflatoxin B1 was visualized under UV and measured with a Turner Fluorometer model 111 (Turner Associates, Palo Alto, CA) and a Dynamax Macintegrator (Rainin Instruments Co., Woburn, MA).

Kernel assay. Maize kernels (Pioneer 3369A and Delta Pine G4666) were obtained from R. L. Brown (USDA/ARS/SRRC, New Orleans, LA). Endosperms and embryos were wounded by inserting a 26-gauge hypodermic needle to a depth of $1 \mathrm{~mm}$ (4). Wounded kernels were surface-sterilized with $5 \%$ sodium hypochlorite, inoculated with $10^{3}$ conidia $(5 \mu \mathrm{l})$ to the wound site, and incubated at $28^{\circ} \mathrm{C}$ in a moist chamber. Five-kernel samples were collected 6 days after inoculation or periodically over 12 days starting 5 days after inoculation. The collected kernels were dissected, separating the embryo and endosperm tissues. Aflatoxins were extracted by crushing the tissues and soaking in $0.3 \mathrm{ml}$ of acetone overnight.
Parasexual manipulation. Parasexual crosses were performed by previously described methods (31). Haploidization was induced in diploids by growing diploids on PDA medium amended with $1 \mu \mathrm{g}$ of methyl-1-(butylcarbamoyl)-2-benzimidozole carbamate per ml (31).

$\alpha$-Amylase analysis. Maize kernels (Pioneer 3369 A) (50 g) were ground to a fine powder, suspended in $40 \mathrm{ml}$ of water, and autoclaved for $20 \mathrm{~min}$ (27). The suspension was inoculated with $2 \times$ $10^{8}$ conidia and incubated while shaking at $28^{\circ} \mathrm{C}$. Samples $(10 \mathrm{ml})$ were collected at $0,2,5,6$, and 8 days after inoculation. Alternatively, conidia were inoculated into starch medium (2\% amylopectin, $0.3 \mathrm{M} \mathrm{NaNO}_{3}, 6 \mathrm{mM} \mathrm{K}_{2} \mathrm{HPO}_{4}, 4 \mathrm{mM} \mathrm{MgSO}_{4}, 7 \mathrm{mM} \mathrm{KCl}$, and $\left.66 \mu \mathrm{M} \mathrm{FeSO}_{4}\right)(27)$, shaken at $28^{\circ} \mathrm{C}$, and sampled after 8 days. For both the kernel suspension and the starch medium, samples were centrifuged and the resulting supernatants filtered through Miracloth (Calbiochem-Behring, San Diego, CA) (27). Samples (15 $\mu$ l) were analyzed by starch-gel electrophoresis $(0.5 \%$ soluble starch and $7.5 \%$ acrylamide) (21). After electrophoresis, the gels were rinsed briefly with distilled water and stained with an iodine solution ( $0.5 \%$ iodine and $5 \%$ potassium iodine). $\alpha$-Amylase activity was visualized as bands that were not stained (21). $\alpha$-Amylase activity was also analyzed by mixing the samples $(0.1 \mathrm{ml})$ with $0.1 \mathrm{ml}$ of $1 \%$ maltoheptaose (Sigma Chemical Co., St. Louis). The mixture was incubated at $40^{\circ} \mathrm{C}$ for $18 \mathrm{~h}$. After heating in boiling water for $5 \mathrm{~min}$ to stop the reaction, $20 \mu \mathrm{l}$ of the mixture was spotted on a TLC plate, and the plate was developed in $n$-propanol/water/ammonium hydroxide (70:30:1). Degradation products of maltoheptaose were visualized by spraying the TLC plate with $30 \%$ sulfuric acid and charring at $100^{\circ} \mathrm{C}(27)$.

Partial purification of $\alpha$-amylase. A. flavus strain 33 was inoculated into $200 \mathrm{ml}$ of starch medium and incubated at $28^{\circ} \mathrm{C}$ with shaking for 8 days. The cultures were centrifuged at $5,000 \times g$ for $10 \mathrm{~min}$, the supernatant was filtered through Miracloth (CalbiochemBehring), and the proteins were precipitated with ammonium sulfate (85\% saturation) (17). After centrifugation at $12,000 \times g$ for $10 \mathrm{~min}$, the pellet was resuspended in $0.1 \mathrm{M}$ potassium phosphate buffer ( $\mathrm{pH}$ 6.5) and dialyzed against the same buffer for $20 \mathrm{~h}$. The solution was then applied to a DEAE-Sephadex A50 column (Phar-

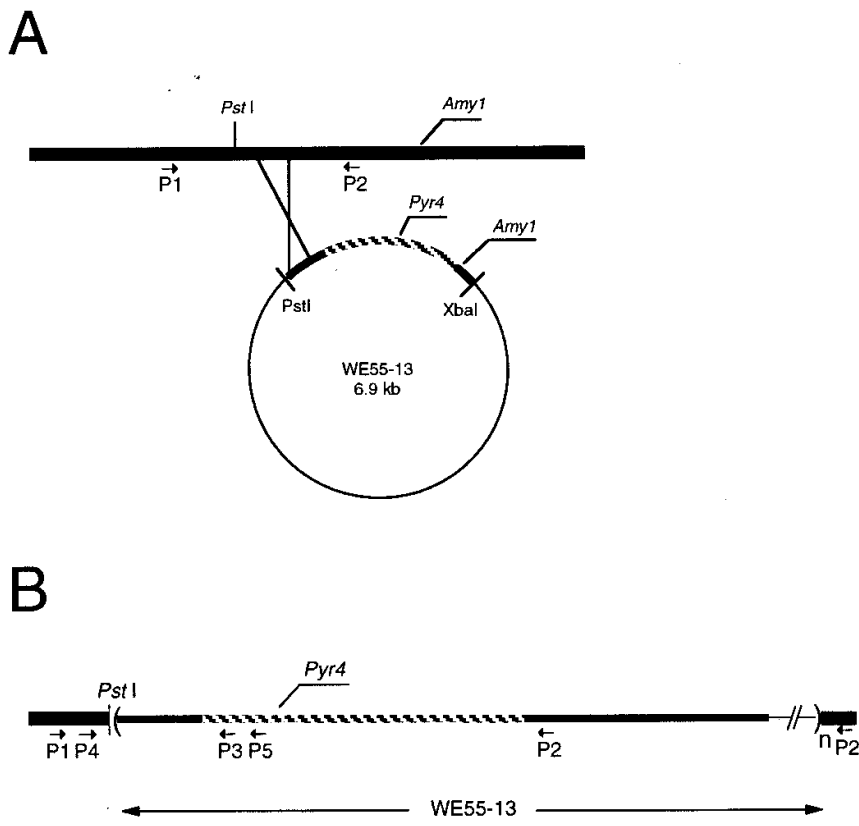

$1 \mathrm{~cm}: 0.5 \mathrm{~kb}$

Fig. 1. Diagram showing A, the integration of gene-disruption vector WE5513 into Amy 1 and $\mathbf{B}$, the positions of the various polymerase chain reaction primers used to characterize the integration. $n=$ Number of copies $(>2)$ that integrated in tandem. 
macia Biotech AB, Uppsala, Sweden). Bound proteins were eluted with a linear salt gradient from 0 to $0.5 \mathrm{M} \mathrm{NaCl}$ in $50 \mathrm{mM}$ potassium phosphate buffer ( $\mathrm{pH}$ 6.5). Fractions containing $\alpha$-amylase were pooled and frozen at $-20^{\circ} \mathrm{C}$. $\alpha$-Amylase activity was determined by the Nelson-Somogyi method (8) with some modifications. Maltose was used as the standard for measuring reducing sugar, and 1 unit of $\alpha$-amylase released $1 \mathrm{mg}$ of maltose from starch in $3 \mathrm{~min}$ at $\mathrm{pH} 6.9$ at $20^{\circ} \mathrm{C}$.

$\alpha$-Amylase inhibitor assay. The $14-\mathrm{kDa}$ trypsin inhibitor protein from maize was obtained from Z. Y. Chen (USDA/ARS/SRRC, New Orleans, LA), who overexpressed the protein in E. coli (9). To test for $\alpha$-amylase inhibitory activity, wheat (Triticum aestivum) $\alpha$-amylase inhibitor (Sigma Chemical Co.) or the $14-\mathrm{kDa}$ protein from maize were mixed with the $\alpha$-amylases of porcine pancreas (Sigma Chemical Co.) or A. flavus and incubated at $37^{\circ} \mathrm{C}$ for $30 \mathrm{~min}$ prior to the addition of the soluble starch. After $10 \mathrm{~min}$ of incubation at $37^{\circ} \mathrm{C}$, the amount of reducing sugars produced was determined. Controls consisted of inhibitor treated with $1.6 \mathrm{mg}$ of proteinase $\mathrm{K}$ per $\mathrm{ml}$ for $16 \mathrm{~h}$ followed by $100^{\circ} \mathrm{C}$ for $30 \mathrm{~min}$.

Glucoamylase analysis. Culture filtrates from $2 \%$ amylopectin medium were assayed for glucoamylase (EC 3.2.1.3) activity (24). Reaction mixtures containing $1 \mathrm{ml}$ of $0.1 \%$ p-nitrophenyl- $\alpha$-Dglucopyranoside (PNP) (Sigma Chemical Co.) in $20 \mathrm{mM} \mathrm{NaOAc}$ $(\mathrm{pH} 4.8)$ and $10 \mu \mathrm{l}$ of the culture filtrates were incubated at $37^{\circ} \mathrm{C}$. Reactions were stopped with $100 \mu \mathrm{l}$ of $1 \mathrm{M} \mathrm{NaOH}$, and absorbance at $420 \mathrm{~nm}$ was measured. One unit of the glucoamylase hydrolyzed $1 \mu \mathrm{mol}$ of PNP per min at $37^{\circ} \mathrm{C}$.

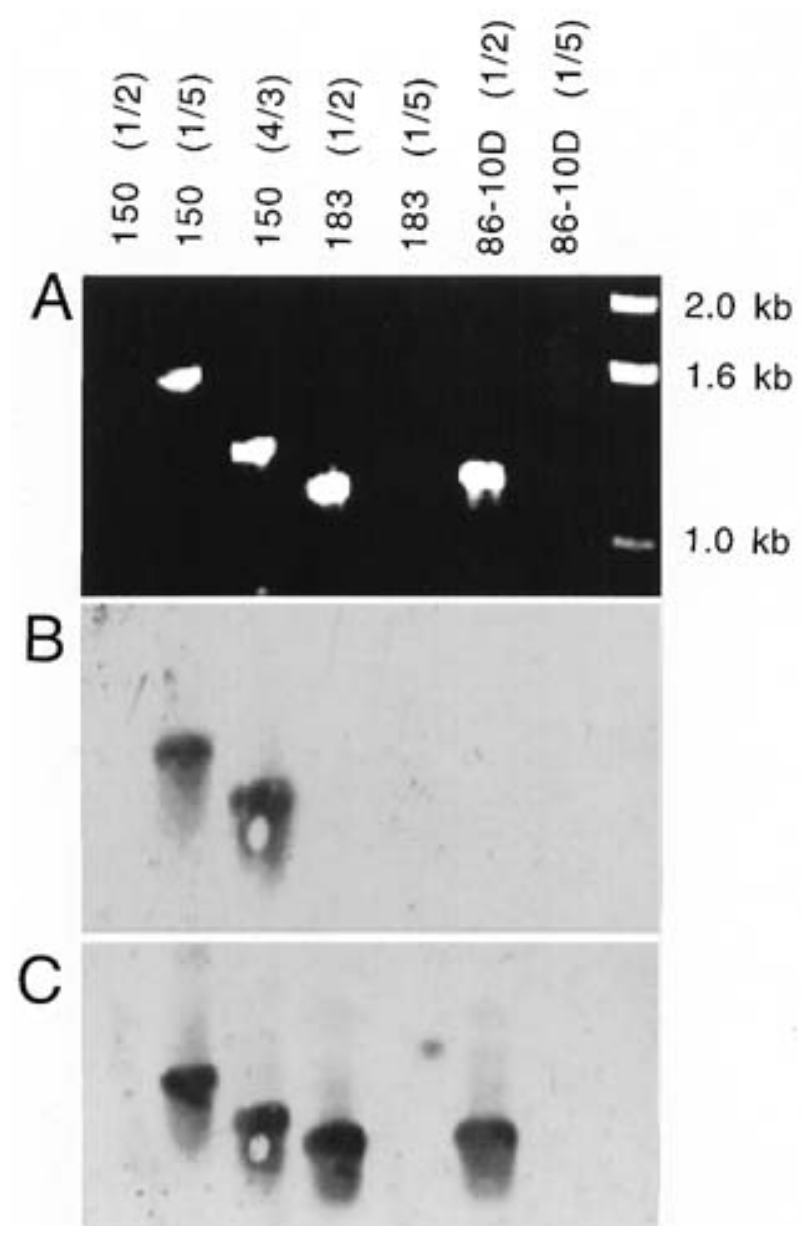

Fig. 2. Agarose gel of the polymerase chain reaction (PCR) products and Southern hybridization analysis of strain 86-10D and transformants 150 and 183. PCR products were $\mathbf{A}$, separated on a $1 \%$ agarose gel containing ethidium bromide, and $\mathbf{B}$ and $\mathbf{C}$, analyzed by Southern hybridization with radiolabeled DNA fragments B, Pyr4 or C, Amy1 as probes. Primer pairs used for PCR reactions are shown in Figure 1.

\section{RESULTS}

Characterization of Amy1. A cosmid clone containing the $\alpha$ amylase gene Amyl from A. flavus was isolated from a genomic library of strain NRRL 3357 (28). Nucleotide sequence analysis indicated that Amyl is nearly identical to the three $\alpha$-amylase genes (Amyl, Amy2, and Amy3) from A. oryzae (26). The genes differ only in the 3 '-nontranslated regions. Alignment of the Amyl sequence with the 425-base pair $3^{\prime}$-nontranslated region of the $A$. oryzae genes revealed $99 \%$ identity to $A m y 3,23 \%$ to Amy1, and $21 \%$ to Amy2.

Amy1 disruption. Amyl in A. flavus strain 86-10D was disrupted with the vector WE55-13 (Fig. 1A). Transformants were screened by PCR with three primer sets. With primers P1 and P2, a 1.2-kb PCR product was indicative of a wild-type Amyl. Primer pairs $\mathrm{P} 1 / \mathrm{P} 5$ and $\mathrm{P} 3 / \mathrm{P} 4$ resulted in PCR products only if WE55-13 was inserted in Amyl (Fig 1B). Of the 250 transformants screened, one (T-150) was identified as having a disrupted Amyl. A 1.6-kb PCR product was obtained from T-150 with primer pair P1/P5 (Fig. 2A). Primer pair P3/P4 yielded a $1.3-\mathrm{kb}$ product. Figure $2 \mathrm{~B}$ and $\mathrm{C}$ shows Southern hybridization results, indicating that these PCR bands contained DNA sequences from both Pyr4 and Amyl, respectively. No PCR product was obtained with primer pair $\mathrm{P} 1 / \mathrm{P} 2$. In contrast, transformant T-183 and strain $86-10 \mathrm{D}$ yielded the expected wild-type Amyl band of $1.2 \mathrm{~kb}$ with $\mathrm{P} 1 / \mathrm{P} 2$ and no bands with P1/P5. The 1.2-kb band hybridized to a Amyl probe but not to a Pyr4 probe (Fig. 2B and C).

To obtain an Amyl-disrupted strain that was also prototrophic for arginine, T-150 was crossed with the aflatoxigenic strain 118. The phenotypes of 103 haploid sectors were determined. Two sectors were selected for further studies; strain 101 contained the disrupted Amyl and strain 33 contained the wild-type Amyl. Both strains were arginine prototrophs and produced aflatoxin.

Southern blots of genomic DNA from strains 33, 118, and 8610D digested with HindIII revealed a 9-kb band when hybridized

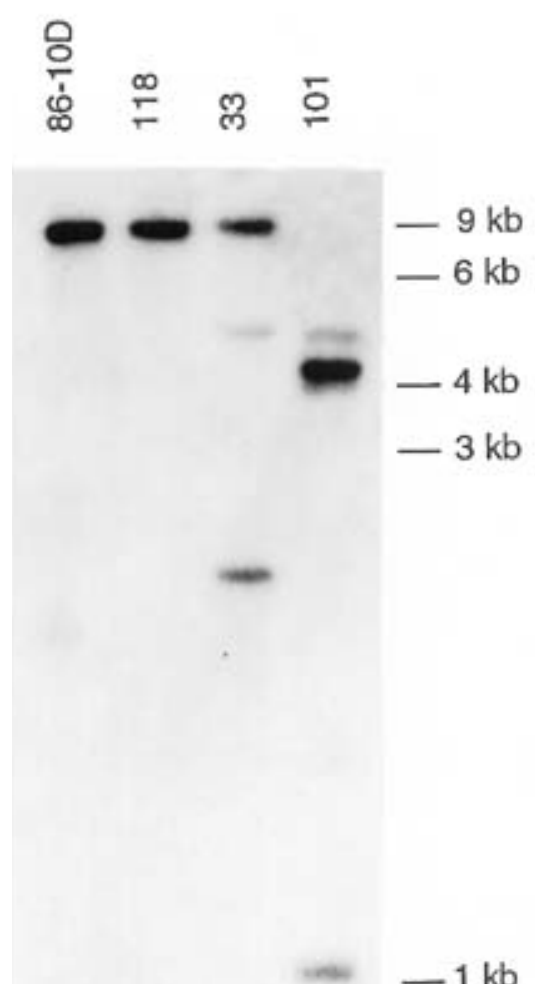

Fig. 3. Southern hybridization analysis of strains 86-10D, 118, 33, and 101 . DNA (3 $\mu \mathrm{g})$ was digested with HindIII, fractionated on an agarose gel, and analyzed by Southern hybridization with radio-labeled DNA fragments of Amyl as a probe. 
with a radio-labeled Amyl probe (Fig. 3). Strain 101 lacked the 9-kb band but contained the predicted 4.3- and 1.3-kb bands, indicating that $A m y l$ was disrupted. To determine the site of integration, DNA from strain 101 was amplified with the PCR primer pair P3/P4 (Fig. 1B). DNA sequence analysis of the $1.3-\mathrm{kb}$ product indicated that Amyl was disrupted by an in-frame integration of WE55-13 at the PstI site of Amyl (Fig. 1B). It was also determined that more than one copy of the vector had integrated in tandem. The additional bands in strain 33 are the disruption vector (WE55-13). Apparently, one copy of the vector in T-150 moved by translocation during the parasexual cross.

Growth and enzyme activity. Strains 101 and 33 were grown on PDA, Czapek-Dox agar (Difco Laboratories, Detroit), and starch agar media. After 5 days, both strains had similar colony diameters on PDA and Czapek-Dox agar media, while on starch agar medium, strain 101 grew at $45 \%$ the rate of strain 33 (Fig. 4). Flooding the starch media plates with an iodine solution revealed a clearing zone around the colony of strain 33, indicating the production of an extracellular $\alpha$-amylase (data not shown). In contrast, strain 101 failed to show a clearing zone. When grown for 1 week in medium containing $2 \%$ amylopectin, strain 101 failed to reduce the viscosity of the medium, whereas strain 33 cultures readily lost viscosity (data not shown). Filtrates from the starch cultures were loaded onto starch polyacrylamide gels, and after electrophoresis, the gels were stained with an iodine solution to reveal $\alpha$-amylase activity. Filtrates from strain 33 showed one band of activity, whereas no band was detected with strain 101 (Fig. 5). The culture filtrates were also incubated with maltoheptaose, and the degradation products were analyzed by TLC. Strain 101 produced predominantly glucose, whereas strain 33 yielded glucose, maltose, and maltotriose (Fig. 6). These data suggested that strain 101 produced a glucoamylase but no $\alpha$-amylase. With PNP as a substrate, similar amounts of glucoamylase were detected in the filtrates of both strains. However, in repeated experiments, glucoamylase was not consistently detected in culture filtrates of the $\alpha$-amylase-producing strains 86-10D and NRRL 3357.

Aflatoxin production. Production of aflatoxin by strain 101 was assessed by a media-shift experiment (Fig. 7). After 4 days of incubation, strain 101 did not produce aflatoxin in either PMS or

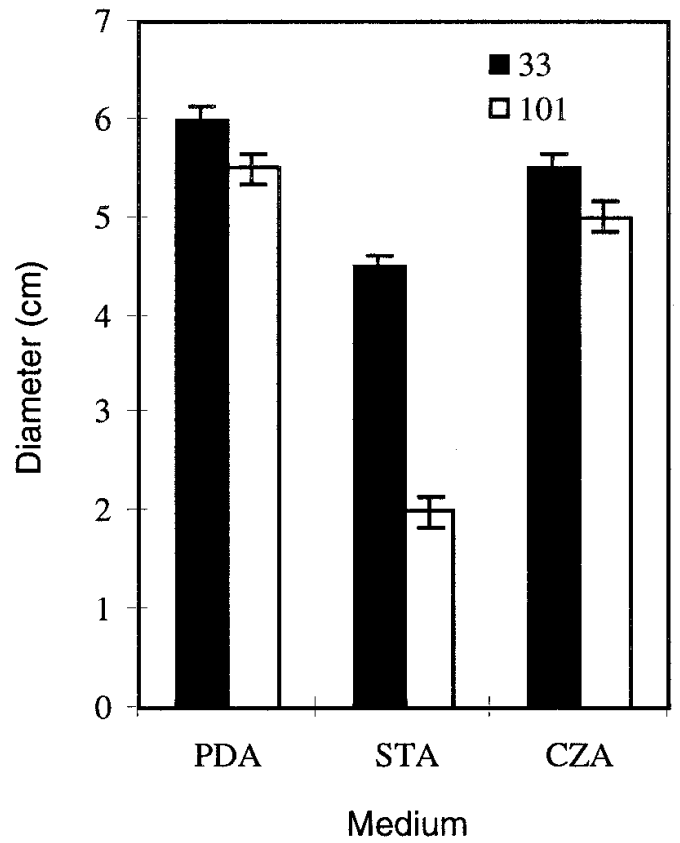

Fig. 4. Growth of strains 33 and 101 on various media. Conidia $\left(10^{4}\right)$ of strains 33 and 101 were inoculated onto starch agar (STA), Czapek-Dox agar (CZA), and potato dextrose agar (PDA) media. Colony diameters were determined after 5 days of incubation. Data represent the average of three replicates and the bars are the standard error. starch medium but produced $17 \mu \mathrm{g}$ of aflatoxin per $\mathrm{ml}$ when shifted to glucose medium. By comparison, strain 33 produced $9 \mu \mathrm{g}$ of aflatoxin per $\mathrm{ml}$ of glucose medium and $1 \mu \mathrm{g} / \mathrm{ml}$ of starch medium. This strain did not produce aflatoxin in PMS medium.

Kernel inoculation. Maize kernels wounded at the embryo or endosperm were inoculated with conidial suspensions of strains 101

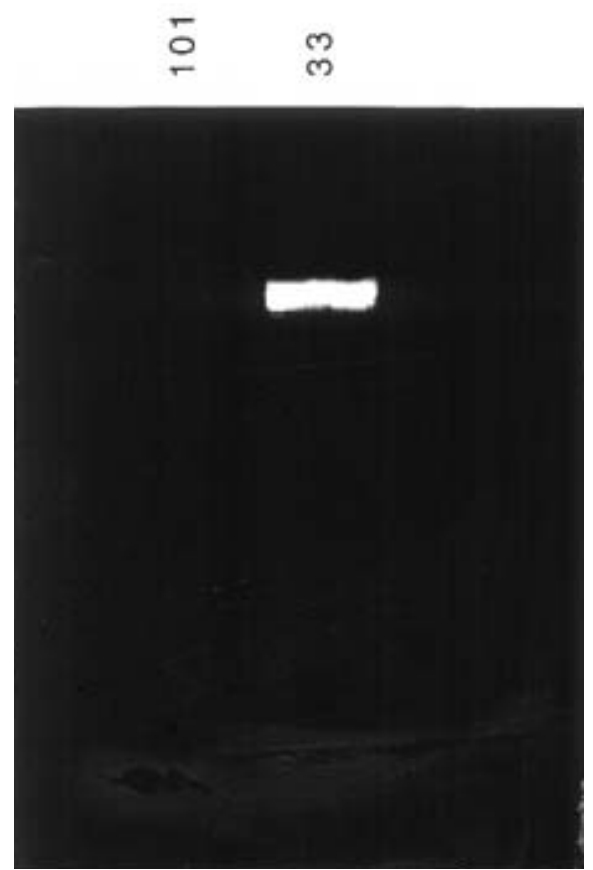

Fig. 5. $\alpha$-Amylase analysis of culture filtrates from strains 33 and 101 grown on $2 \%$ starch medium. Proteins in the culture filtrates $(15 \mu \mathrm{l})$ were separated by electrophoresis on a starch polyacrylamide gel. The gel was washed briefly with distilled water and then stained with an iodine solution. $\alpha$-Amylase activity was detected as the band not stained by the iodine.

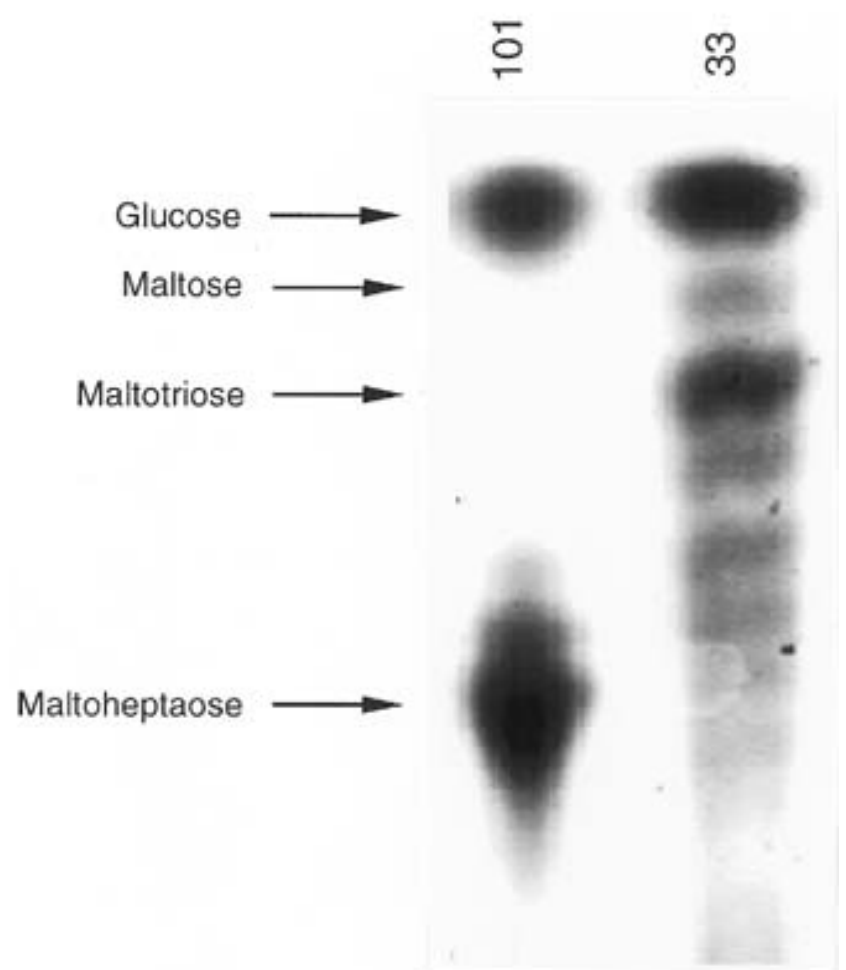

Fig. 6. Thin-layer chromatographic (TLC) analysis of maltoheptaose digested by culture filtrates from strains 33 and 101 grown on $2 \%$ starch medium. Culture filtrates were incubated $18 \mathrm{~h}$ at $40^{\circ} \mathrm{C}$ with maltoheptaose. After chromatographic development, products were detected by spraying the TLC plate with $30 \%$ sulfuric acid and charring at $100^{\circ} \mathrm{C}$. 
and 33. Three days after inoculation, sporulation was observed at the wound sites, and the number of conidia produced was similar for the two strains (data not shown). Both strains produced similar amounts of aflatoxin in the embryo-wounded kernels, ranging from 300 to $400 \mu \mathrm{g}$ of aflatoxin per g of kernels (data not shown). When the endosperm of kernels was wounded, aflatoxin was occasionally detected in those inoculated with strain 101, whereas strain 33 produced aflatoxin in nearly all kernels (Table 1). Aflatoxin was produced in kernels inoculated with strain 33 after 8, 9, 10, and 17 days of incubation. Aflatoxin was detected in both the embryo and endosperm tissues of these kernels. In this same experiment, aflatoxin was detected in only one kernel inoculated with strain 101. On day 10, one kernel contained aflatoxin in the embryo tissue but not the endosperm. Strains 33 and 101 also were inoculated onto maize kernels after removal of the embryo tissue. Both strains grew and sporulated on the kernels; however, only strain 33 produced aflatoxin (Table 2).

$\alpha$-Amylase inhibition. The $14-\mathrm{kDa}$ protein from maize and the $\alpha$-amylase inhibitor from wheat were tested for the ability to inhibit the $\alpha$-amylases from $A$. flavus and porcine pancreas (Table 3 ). The maize protein at 6 and $9 \mu \mathrm{M}$ inhibited the $\alpha$-amylase from $A$. flavus by 49 and $60 \%$, respectively, but had essentially no effect on the porcine enzyme. The wheat $\alpha$-amylase inhibitor was not effective against the $\alpha$-amylase from $A$. flavus but inhibited the

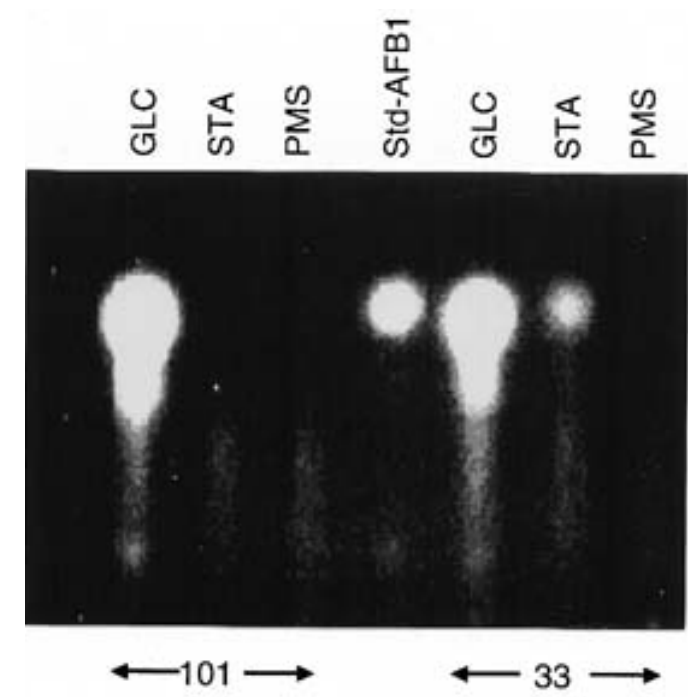

Fig. 7. Effect of various media on aflatoxin production by strains 33 and 101 . Microtiter plates (24 wells) containing $1 \mathrm{ml}$ of peptone mineral salts (PMS) medium were inoculated with conidia $\left(5 \times 10^{6}\right)$. The microtiter plates were incubated at $28^{\circ} \mathrm{C}$ for 2 days. The medium was then replaced with $2 \%$ starch (STA), 2\% glucose (GLC), or PMS. Aflatoxin was analyzed by thin-layer chromatography and photographed under UV irradiation. The lane marked AFB1 is the aflatoxin B1 standard.

TABLE 1. Aflatoxin production by Aspergillus flavus strains 33 and 101 in endosperm-wounded maize kernels

\begin{tabular}{lcccccccc}
\hline & \multicolumn{2}{c}{ Kernels with aflatoxin $^{\mathrm{b}}$} & & \multicolumn{2}{c}{ Endosperm $^{\mathrm{c}}$} & & \multicolumn{2}{c}{ Embryo $^{\mathrm{c}}$} \\
\cline { 2 - 3 } \cline { 7 - 8 } Days $^{\mathrm{a}}$ & 33 & 101 & & 33 & 101 & & 33 & 101 \\
\hline 5 & 0 & 0 & & 0 & 0 & & 0 & 0 \\
6 & 0 & 0 & & 0 & 0 & & 0 & 0 \\
7 & 0 & 0 & & 0 & 0 & & 0 & 0 \\
8 & 4 & 0 & & 4 & 0 & & 4 & 0 \\
9 & 3 & 0 & & 3 & 0 & & 3 & 0 \\
10 & 5 & 1 & & 5 & 0 & & 5 & 1 \\
17 & 5 & 0 & & $\ldots$ & $\ldots$ & & $\ldots$ & $\ldots$ \\
\hline
\end{tabular}

a Days after inoculation.

b Number in the five-kernel sample containing aflatoxin.

c Number in the five-kernel sample containing aflatoxin in the endosperm or embryo tissues.

d Not determined. porcine enzyme by $95 \%$. Proteinase K treatment completely abolished the inhibitory activity of both the maize and wheat proteins.

\section{DISCUSSION}

A. flavus is capable of growing and reproducing on medium containing starch as the sole carbon source. Like other filamentous fungi, A. flavus produces extracellular hydrolases to degrade starch to glucose and maltose. In this study, we have examined $\alpha$-amylase and its role in the production of the secondary metabolite aflatoxin in culture and in wounded maize kernels. A. flavus contains a single $\alpha$-amylase gene that we designated Amyl. The nucleotide sequence of Amyl was identical to the nine exons and eight introns of the three $\alpha$-amylase genes from $A$. oryzae (26). The $3^{\prime}$-nontranslated region of the A. flavus gene is $99 \%$ identical to Amy3.

Disruption of Amyl completely eliminated all detectable $\alpha$-amylase and reduced growth on starch medium by $55 \%$. Growth of the Amyl-disrupted strain 101 on starch medium was likely due to its production of an extracellular glucoamylase. In a previous study, we showed that wild-type $A$. flavus released $4.5 \mathrm{mM}$ glucose after 2 days of growth in $2 \%$ starch medium (27). The data also indicated that expression of the aflatoxin genes, as measured by a Verl-promoter-GUS reporter, occurred at glucose concentrations as low as $1 \mathrm{mM}$ (27). In this study, strains 33 and 101 produced aflatoxin when mycelia of the strains were shifted to medium containing $111 \mathrm{mM}$ glucose. Shifting these strains to a $2 \%$ starch carbon source induced aflatoxin production only in strain 33. These observations indicate that $\alpha$-amylase produced by A. flavus generates sugar concentrations sufficient to induce aflatoxin, whereas the amount of glucose produced by glucoamylase does not. These data also support our previous hypothesis that the aflatoxin-inducing activity in filtrates of maize kernels colonized by $A$. flavus was due, in part, to the $15 \mathrm{mM}$ glucose in the filtrates (27).

Fungal growth and aflatoxin production in wounded maize kernels were studied recently by Keller et al. (16), using a norsolorinic acid-accumulating strain of $A$. parasiticus, and by Brown et al. (4), using a strain of A. flavus containing a GUS-reporter construct. Our data support their conclusions that the embryo tissue is preferred for colonization and aflatoxin accumulation. Strains 101 and 33 both produce aflatoxin in all kernels wounded at the embryo. These observations argue that the high lipid content in the embryo

TABLE 2. Aflatoxin production in the endosperm tissue of maize kernels by Aspergillus flavus strains 33 and $101^{\mathrm{a}}$

\begin{tabular}{lccc}
\hline & \multicolumn{3}{c}{ Aflatoxin B1 $(\mu \mathrm{g} / \mathrm{g})$} \\
\cline { 2 - 4 } Strain & Day 6 $^{\mathrm{b}}$ & Day 7 & Day 15 \\
\hline 33 & $28 \pm 40^{\mathrm{c}}$ & $23 \pm 4$ & $77 \pm 17$ \\
101 & 0 & 0 & 0 \\
\hline
\end{tabular}

a Embryo tissue was removed from kernels.

b Days after inoculation.

${ }^{c}$ Data are the mean of five kernels \pm the standard deviation.

TABLE 3. The effect of the 14-kDa protein from maize and the wheat inhibitor on the $\alpha$-amylases from Aspergillus flavus and porcine pancreas

\begin{tabular}{|c|c|c|c|c|c|}
\hline \multirow[b]{3}{*}{$\alpha$-Amylase ${ }^{a}$} & \multicolumn{5}{|c|}{ Percent inhibition $^{b}$} \\
\hline & \multicolumn{2}{|c|}{ Maize $(6 \mu \mathrm{M})$} & \multirow{2}{*}{$\frac{\text { Maize }(9 \mu \mathrm{M})}{\text { Without }}$} & \multicolumn{2}{|c|}{ Wheat $(7 \mu \mathrm{M})$} \\
\hline & Without ${ }^{\mathrm{c}}$ & With & & Without & With \\
\hline A. flavus & $49 \pm 2^{d}$ & $0 \pm 3$ & $60 \pm 1$ & $5 \pm 2$ & $0 \pm 4$ \\
\hline Porcine & $2 \pm 3$ & $4 \pm 3$ & $\ldots^{\mathrm{e}}$ & $95 \pm 7$ & $10 \pm 5$ \\
\hline
\end{tabular}

a There was 0.03 units of enzyme used.

b Maize 14-kDa protein or wheat $\alpha$-amylase inhibitor was incubated with the $\alpha$-amylases at $37^{\circ} \mathrm{C}$ for $30 \mathrm{~min}$ prior to the addition of soluble starch. The amount of reducing sugars was measured after $10 \mathrm{~min}$ at $37^{\circ} \mathrm{C}$.

c Without or with proteinase $\mathrm{K}$ treatment.

${ }^{\mathrm{d}}$ Data are the mean of three experiments \pm the standard deviation.

e Not determined. 
rather than $\alpha$-amylase is responsible for the induction of aflatoxin. In contrast to aflatoxin production in embryo-wounded kernels, the $\alpha$-amylase-deficient strain 101 rarely produced aflatoxin in endosperm-wounded kernels. In the few kernels in which aflatoxin was produced, aflatoxin was produced in the embryo not the endosperm, suggesting that cracks in the pericarp near the embryo allowed the fungus to reach this tissue. The wild-type strain 33 consistently produced aflatoxin in both the embryo and endosperm. Both Keller et al. (16) and Brown et al. (4) showed that the fungus grew from the endosperm wound site along the aleurone layer. Norsolorinic acid was produced in the aleurone layer, indicating that aflatoxin was also produced in this tissue (16). Our results suggest that $\alpha$ amylase facilitates the growth of $A$. flavus from a wound in endosperm to the embryo and is important for aflatoxin production. Keller et al. (16) suggested that the aflatoxin measured in the endosperm was the result of diffusion from the embryo. Our results indicate that aflatoxin can be produced in the endosperm tissue. The observation that only strain 33 produced aflatoxin on kernels with the embryo tissue removed implicates the direct involvement of $\alpha$-amylase in aflatoxin production in the endosperm tissue.

Maize kernels assayed in our study have been characterized as susceptible to A. flavus infection and aflatoxin production (R. L. Brown, personal communication). Recently published evidence by Brown et al. (5) showed that growth and aflatoxin production in embryo-wounded and endosperm-wounded kernels were similar in a susceptible inbred of maize (33-16). In a resistant inbred (MI82), growth and aflatoxin production were significantly higher in the embryo-wounded kernels. These authors interpreted the data to indicate that a viable embryo is required for expression of the resistant phenotype. Based on evidence presented on the $\alpha$-amylasedeficient strain 101, we suggest that the endosperm of inbred MI82 contains molecules that inhibit the growth of A. flavus and aflatoxin biosynthesis. Such an inhibitor was recently isolated by Chen et al. (10), who observed an abundant $14-\mathrm{kDa}$ protein in extracts from A. flavus-resistant maize kernels including inbred MI82. The protein was estimated to account for 13 to $22 \%$ of the total extracted protein in resistant genotypes, but only 0 to $6.4 \%$ in susceptible genotypes (10). When purified, the 14-kDa protein was identified as a trypsin inhibitor that inhibited conidia germination and hyphal growth of A. flavus and other fungi (9). At the 1998 Aflatoxin Elimination Workshop (St. Louis, MO, October 25-27), R. L. Brown presented evidence showing that the protein also inhibited the $\alpha$-amylase from A. flavus, suggesting that it belongs to a group of bifunctional trypsin/amylase inhibitors (23). In this study, we have further documented that the $14-\mathrm{kDa}$ protein inhibits the $\alpha$-amylase from $A$. flavus. Collectively, these results suggest that the 14-kDa protein directly inhibits fungal growth in the maize kernel and also limits growth in the endosperm tissue by inhibiting the degradation of starch. To our knowledge, the 14-kDa inhibitor from maize is the first reported inhibitor of a fungal $\alpha$-amylase. A 29.6-kDa inhibitor was previously isolated from maize; however, this protein was inactive against the $\alpha$-amylase from $A$. oryzae (3). The 29.6-kDa protein was initially identified as an inhibitor of $\alpha$ amylase in the insect Tribolium castaneum. We used the $\alpha$-amylase from A. flavus to screen protein extracts from seeds and found that several species contain potent inhibitors of the enzyme (A. M. Fakhoury and C. P. Woloshuk, unpublished data). Our data suggest that other inhibitors of fungal $\alpha$-amylase exist and may play a role as a defense mechanism by limiting access to important carbon sources.

\section{ACKNOWLEDGMENTS}

Support for this research was provided by USDA Cooperative agreements 58-6435-4-116 and 58-6435-8-118. This report constitutes Journal Publication 15945 of the Purdue University Agriculture Experimental Station. We thank Z.-Y. Chen and R. L. Brown for providing the maize trypsin inhibitor and for their helpful discussion.

\section{LITERATURE CITED}

1. Abdollahi, A., and Buchanan, R. L. 1981. Regulation of aflatoxin biosynthesis: Induction of aflatoxin production by various carbohydrates. J. Food Sci. 46:633-635.

2. Abdollahi, A., and Buchanan, R. L. 1981. Regulation of aflatoxin biosynthesis: Characterization of glucose as an apparent inducer of aflatoxin production. J. Food Sci. 46:143-146.

3. Blanco-Labra, A., and Iturbe-Chinas, F. A. 1981. Purification and characterization of an $\alpha$-amylase inhibitor from maize (Zea mays). J. Food Biochem. 5:1-17.

4. Brown, R. L., Cleveland, T. E., Payne, G. A., Woloshuk, C. P., Campbell, K. W., and White, D. G. 1995. Determination of resistance to aflatoxin production in maize kernels and detection of fungal colonization using an Aspergillus flavus transformant expressing Escherichia coli $\beta$-glucuronidase. Phytopathology 85:983-989.

5. Brown, R. L., Cleveland, T. E., Payne, G. A., Woloshuk, C. P., and White, D. G. 1997. Growth of an Aspergillus flavus transformant expressing Escherichia coli $\beta$-glucuronidase in maize kernels resistant to aflatoxin production. J. Food Prot. 60:84-87.

6. Buchanan, R. L., and Stahl, H. G. 1984. Ability of various carbon sources to induce and support aflatoxin synthesis by Aspergillus parasiticus. J. Food Saf. 6:271-279.

7. Burow, G. B., Nesbitt, T. C., Dunlap, J., and Keller, N. P. 1997. Seed lipoxygenase products modulate Aspergillus mycotoxin biosynthesis. Mol. Plant-Microbe Interact. 10:380-387.

8. Chaplin, M. F. 1994. Monosaccharides. Pages 1-41 in: Carbohydrate Analysis: A Practical Approach. M. F. Chaplin and J. F. Kennedy, eds. IRL Press, Oxford.

9. Chen, Z. Y., Brown, R. L., Lax, A. R., Cleveland, T. E., and Russin, J. S. 1999. Inhibition of plant-pathogenic fungi by a corn trypsin inhibitor overexpressed in Escherichia coli. Appl. Environ. Microbiol. 65:1320-1324.

10. Chen, Z.-Y., Brown, R. L., Lax, A. R., Guo, B. Z., Cleveland, T. E., and Russin, J. S. 1998. Resistance to Aspergillus flavus in corn kernels is associated with a 14-kDa protein. Phytopathology 88:276-281.

11. Egel, D. S., Cotty, P. J., and Elias, K. S. 1994. Relationships among isolates of Aspergillus sect. flavi that vary in aflatoxin production. Phytopathology 84:906-912.

12. Fabbri, A. A., Fanelli, C., Panfili, G., Passi, S., and Fasella, P. 1983. Lipoperoxidation and aflatoxin biosynthesis by Aspergillus parasiticus and A. flavus. J. Gen. Microbiol. 129:3447-3452.

13. Failla, L. J., Lynn, D., and Niehaus, W. G. 1986. Correlation of $\mathrm{Zn}^{2+}$ content with aflatoxin content of corn. Appl. Environ. Microbiol. 52:73-74.

14. Fanelli, C., Fabbri, A. A., and Passi, S. 1981. Aflatoxin production by Aspergillus flavus during incubation with lipid sources in culture media. Trans. Br. Mycol. Soc. 77:416-419.

15. Flaherty, J. E., Weaver, M. A., Payne, G. A., and Woloshuk, C. P. 1995. A beta-glucuronidase reporter gene construct for monitoring aflatoxin biosynthesis in Aspergillus flavus. Appl. Environ. Microbiol. 61:2482-2486.

16. Keller, N. P., Butchko, R. A. E., Sarr, B., and Phillips, T. D. 1994. A visual pattern of mycotoxin production in maize kernels by Aspergillus spp. Phytopathology 84:483-488.

17. Khoo, S. L., Amirul, A. A., Kamaruzaman, M., Nazalan, N., and Azizan, M. N. 1994. Purification and characterization of $\alpha$-amylase from Aspergillus flavus. Folia Microbiol. 39:392-398.

18. Luchese, R. H., and Harrigan, W. F. 1993. Biosynthesis of aflatoxinThe role of nutritional factors. J. Appl. Bacteriol. 74:5-14.

19. Maniatis, T., Fritsch, E. F., and Sambrook, J. 1982. Molecular Cloning: A Laboratory Manual. Cold Spring Harbor Laboratory, Cold Spring Harbor, NY.

20. Minto, R. E., and Townsend, C. A. 1997. Enzymology and molecular biology of aflatoxin biosynthesis. Chem. Rev. 97:2537-2555.

21. Mishra, R. S., and Maheshwart, R. 1996. Amylases of the thermophilic fungus Thermomyces lanuginosis: Their purification, properties, action on starch and response to heat. J. Biosci. 21:653-672.

22. Reddy, M. J., Shetty, H. S., Fanelli, C., and Lacey, J. 1993. Role of seed lipids in Aspergillus parasiticus growth and aflatoxin production. J. Sci. Food Agric. 59:177-181.

23. Ryan, C. A. 1990. Proteinase inhibitors in plants: Genes for improving defenses against insects and pathogens. Annu. Rev. Phytopathol. 28:425449.

24. Sun, Z., and Henson, C. A. 1990. Degradation of native starch granules by barley $\alpha$-glucosidases. Plant Physiol. 94:320-327.

25. Widstrom, N. W., McMillian, W. W., Wilson, D. M., Garland, D. L., and Glover, D. V. 1984. Growth characteristics of Aspergillus flavus on agar infused with maize kernel homogenates and aflatoxin contamination of whole kernel samples. Phytopathology 74:887-890.

26. Wirsel, S., Lachmund, A., Wildhardt, G., and Ruttkowski, E. 1989. Three $\alpha$-amylase genes of Aspergillus oryzae exhibit identical intron-exon or- 
ganization. Mol. Microbiol. 3:3-14.

27. Woloshuk, C. P., Cavaletto, J. R., and Cleveland, T. E. 1997. Inducers of aflatoxin biosynthesis from colonized maize kernels are generated by an amylase activity from Aspergillus flavus. Phytopathology 87: 164-169.

28. Woloshuk, C. P., and Payne, G. A. 1994. The alcohol dehydrogenase adh1 is induced in Aspergillus flavus grown on medium conductive to aflatoxin biosynthesis. Appl. Environ. Microbiol. 60:670-676.

29. Woloshuk, C. P., Payne, G. A., Foutz, K. R., Brewer, J. F., Bhatnagar, D., and Cleveland, T. E. 1994. Molecular characterization of aflR, a regulatory locus for aflatoxin biosynthesis. Appl. Environ. Microbiol. 60:24082414.

30. Woloshuk, C. P., Seip, E. R., Payne, G. A., and Adkins, C. R. 1989. Genetic transformation system for the aflatoxin-producing fungus Aspergillus flavus. Appl. Environ. Microbiol. 55:86-90.

31. Woloshuk, C. P., Yousibova, G. L., Rollins, J. A., Bhatnagar, D., and Payne, G. A. 1995. Molecular characterization of the afl-1 locus in Aspergillus flavus. Appl. Environ. Microbiol. 61:3019-3023. 